\title{
Decreased expression of the carboxyl terminus of heat shock cognate 70 interacting protein in human gastric cancer and its clinical significance
}

\author{
LEI GAN $^{1 *}$, DONG-BO LIU ${ }^{1 *}$, HAI-FENG LU ${ }^{2 *}$, GUO-XIAN LONG ${ }^{1}$, QI MEI ${ }^{1}$, \\ GUANG-YUAN HU ${ }^{1}$, HONG QIU ${ }^{1}$ and GUO-QING HU ${ }^{1}$ \\ ${ }^{1}$ Department of Oncology, Tongji Hospital, ${ }^{2}$ Department of Pharmacology, Tongji Medical College, \\ Huazhong University of Science and Technology, Wuhan, P.R. China
}

Received April 5, 2012; Accepted July 2, 2012

DOI: 10.3892/or.2012.1957

\begin{abstract}
The carboxyl terminus of heat shock cognate 70 interacting protein (CHIP) is an E3 ubiquitin ligase, which can promote ubiquitylation and degradation of many tumor-related proteins. However, the expression of CHIP in human gastric cancer has not been investigated. In this study, the mRNA and protein levels of CHIP expression in 53 cases of gastric cancer and matched normal tissues were determined by quantitative real-time PCR, western blotting and immunohistochemistry. We showed that CHIP was registered from basal to middle portions of normal gastric mucosa. CHIP expression was notably decreased or lost in human gastric cancer samples compared with the matched normal non-cancer samples. The correlations between CHIP downregulation and the clinicopathological characteristics were also evaluated. The expression of CHIP was significantly lower in the gastric cancer samples compared to the matched normal samples at both mRNA and protein levels $(\mathrm{P}<0.05$ and $\mathrm{P}<0.05$, respectively). More importantly, the downregulation of CHIP was correlated with TNM stage $(\mathrm{P}=0.048)$ and lymph node metastasis $(\mathrm{P}=0.010)$ at the mRNA levels. In addition, the downregulation of CHIP was correlated with lymph node metastasis $(\mathrm{P}=0.021)$ and tumor differentiation $(\mathrm{P}=0.009)$ at the protein levels. Taken together, at both mRNA and protein levels, the decreased expression of CHIP was correlated with lymph node metastasis. Furthermore, our study suggests that a negative correlation exists between CHIP expression and tumor malignancy in human gastric cancer.
\end{abstract}

Correspondence to: Dr Guo-Qing Hu, Department of Oncology, Tongji Hospital, Tongji Medical College, Huazhong University of Science and Technology, 1095 Jiefang Road, Hubei, Wuhan 430030, P.R. China

E-mail: gqhu@tjh.tjmu.edu.cn

${ }^{*}$ Contributed equally

Key words: carboxyl terminus of heat shock cognate 70 interacting protein, gastric cancer, clinicopathological characteristics

\section{Introduction}

Gastric cancer (GC), is the fourth most common type of malignancy and the second most common cause of cancer death in the world (1), over $70 \%$ of the gastric cancer cases occur in the developing countries, and half of the total cases occur in Eastern Asia (mainly in China) (2). Gastric cancer is a biologically and genetically heterogeneous carcinoma (3), and accumulating evidence has suggested that various genetic and epigenetic alterations are related to human gastric cancer (4), including overexpression of oncogenes such as $c$-met and $c$-erbB2 (5-7), inactivation of tumor suppressor genes such as p53, $\beta$-catenin and PTEN (8-10), as well as alterations of cell cycle regulators, cell adhesion molecules and DNA repair genes (4). Sakata et al have reported that methylation of $H A C E I$ (HECT domain and ankyrin repeat containing E3 ubiquitinprotein ligase 1) and downregulation of EGFL8 (epidermal growth factor-like domain 8 ) were intimately related to gastric cancer $(11,12)$. The majority of gastric cancer cases are diagnosed at advanced stages which are generally resistant to chemotherapy or radiotherapy, and the current 5-year survival rate of gastric cancer is $<20 \%(13,14)$. Nevertheless, if gastric cancer could be diagnosed at an early stage, it is a curative disease. Therefore, it is crucial to identify clinically useful biomarkers that can diagnose gastric cancer at an early stage (15). Thus, further investigations to identify genetic changes as new parameters for assessing the progression of gastric cancer are necessary.

Carboxyl terminus of heat shock cognate 70 interacting protein (CHIP) is a cytoplasmic protein containing a 34-amino-acid tetratricopeptide repeat (TPR) domain (16), which is referred to in protein-protein interactions (17), an intervening charged domain and a 'U-box' domain (18). The U-box domain contains an E3 ubiquitin ligase activity and can induce ubiquitylation and subsequent proteasome-dependent degradation of tumor-related proteins $(19,20)$. Therefore, many studies have focused on the relationship between CHIP and carcinomas. For instance, CHIP acts as an upstream regulator of oncogenic pathways and inhibits cell growth and metastatic potential by degrading oncogenic proteins including SRC-3 in breast cancer (21). And a recent report demonstrated CHIP 
contributes to the oncogenesis of glioma (22). Moreover, a present study found that CHIP interacts with endogenous Met in lung cancer cells (H358 cells) via inducing the ubiquitination and degradation of Met receptor and CHIP inhibits the tumor growth by decreasing Met in vivo (23). However, the expression of CHIP in human gastric cancer remains unknown. Therefore, the current study was carried out to evaluate the expression of CHIP in gastric cancer and to explore the correlations between CHIP expression and clinicopathological characteristics of gastric cancer. In our present study, we found the decreased expression of CHIP is associated with the clinically aggressive phenotype in gastric cancer.

\section{Materials and methods}

Clinical patient samples. Fifty-three patients (median age, 56.0 years; range, 16-77 years; 32 males, 21 females) with primary gastric cancer were included in this study. A total of 53 paired cancerous samples and matched adjacent normal mucosa located at least $6 \mathrm{~cm}$ away from the tumor site were collected from patients who underwent initial surgical resection at Tongji Hospital, Tongji Medical College (Wuhan, China) between April 2011 and January 2012. The non-cancerous samples were confirmed to be without any tumor cell infiltration by histological examination. All patients were pathologically diagnosed as stomach carcinoma, without any metastatic diseases or any other tumors. Informed written consent was obtained from all the patients and the study was approved by the local ethics committee. For each sample, a portion of the lesion was frozen in liquid nitrogen immediately after surgical resection and then stored at $-80^{\circ} \mathrm{C}$, while another portion was fixed in $10 \%$ formalin-buffered and paraffin-embedded.

Total RNA extraction and first strand cDNA synthesis. RNAiso Plus extraction of total RNA was carried out essentially according to the manufacturer's instructions (Takara, Dalian, China). The RNA pellets were dissolved in $40 \mu \mathrm{l}$ of RNase-free water and stored at $-80^{\circ} \mathrm{C}$. RNA integrity was assessed prior to cDNA synthesis. The concentration of total RNA was measured by UNICO UV-2800 spectrophotometric readings (Shanghai, China) and the OD260/OD280 ratio of all RNA samples were up to 2.0. The first strand cDNA was synthesized using the RevertAid $^{\mathrm{TM}}$ First Strand cDNA Synthesis kit (Fermentas, MBI, Lithuania) according to the manufacturer's protocol.

Polymerase chain reaction and quantitative real-time PCR. Polymerase chain reactions (PCR) were performed in a total volume of $20 \mu \mathrm{l}$, containing $10 \mu \mathrm{l} 2 \mathrm{X}$ Taq PCR MasterMix, $0.5 \mu \mathrm{l}$ of each primer (10 pM each), $1 \mu \mathrm{l}$ cDNA template and $8 \mu \mathrm{l}$ sterile water. The amplification protocol consisted of an initial denaturation at $94^{\circ} \mathrm{C}$ for $5 \mathrm{~min}$, followed by 35 cycles of denaturation for $30 \mathrm{sec}$ at $94^{\circ} \mathrm{C}$, annealing for $45 \mathrm{sec}$ at $64^{\circ} \mathrm{C}$ and extension for $30 \mathrm{sec}$ at $72^{\circ} \mathrm{C}$, followed by a final extension at $72^{\circ} \mathrm{C}$ for $10 \mathrm{~min}$. The PCR products were verified by $1.5 \%$ agarose gel electrophoresis and analyzed using the Gel Doc ${ }^{\mathrm{TM}}$ XR Imaging System (Bio-Rad, Foster City, CA, USA). The PCR and real-time PCR primers for $C H I P(151 \mathrm{bp})$ : forward, 5'-GAGGCCAAGCACGACAAGTAC-3'; reverse, 5'-TGATGCCACTGGGCGTGATGC-3'. GAPDH (218 bp): forward, 5'-GGTCGGAGTCAACGGATTTG-3'; reverse,
5'-GGAAGATGGTGATGGGATTTC-3'. The primers of CHIP and GAPDH genes were designed by Primer Premier 5.0 software (Premier Biosoft International, Palo Alto, CA, USA). Quantitative real-time PCR was performed with a continuous fluorescence detector - StepOne machine (Applied Biosystems, Forster City, CA, USA). Quantitative real-time PCR reaction was carried out using SuperReal PreMix SYBR-Green kit (Tiangen Biotech Co., Ltd., Beijing, China). The cycling parameters were: initial denaturation at $95^{\circ} \mathrm{C}$ for $15 \mathrm{~min}$, followed by 40 cycles at $95^{\circ} \mathrm{C}$ for $10 \mathrm{sec}, 64^{\circ} \mathrm{C}$ for $30 \mathrm{sec}$ and $72^{\circ} \mathrm{C}$ for $30 \mathrm{sec}$. The cycling was followed by melting curve analysis to distinguish specificity of the PCR products. CHIP expression was normalized with glyceraldehyde-3-phosphate dehydrogenase $(G A P D H)$ as an internal control in the same sample. Each sample was run three times. No template controls (no cDNA in PCR reaction) were run to detect unspecific or genomic amplification and primer dimerization. The average threshold cycle $(\mathrm{Ct})$ for three replicates per sample was used to calculate $\Delta \mathrm{Ct}$. Relative quantification of CHIP expression was calculated with the $2^{-\Delta \Delta \mathrm{Ct}}$ method.

Tissue immunohistochemistry and immunoblotting. Tissue immunohistochemistry (IHC) was performed using a standard peroxidase-based staining method. Tissue sections $(4 \mu \mathrm{m})$ were dewaxed in xylene, hydrated with graded ethanol. Then antigen retrieval was performed by pretreatment of the slides in $0.01 \mathrm{M}$ citrate buffer ( $\mathrm{pH}$ 6.0) using a microwave oven. Subsequently, the sections were treated with $3 \%$ hydrogen peroxide $\left(\mathrm{H}_{2} \mathrm{O}_{2}\right)$ for $10 \mathrm{~min}$ in order to block endogenous peroxidase. The sections were washed with $0.01 \mathrm{M}$ phosphatebuffered saline (PBS) ( $\mathrm{pH} 7.4)$, and were incubated with rabbit anti-CHIP antibody (dilution 1:250; Abcam Co., USA) overnight at $4^{\circ} \mathrm{C}$. The sections were then washed with 0.01 M PBS and incubated with biotinylated goat anti-rabbit IgG (SP9000, Zhongshan Goldenbridge Biotechnology Co., Ltd., Beijing, China). For each sample, the omission of primary antibody was used as a negative control. In addition, total protein was extracted only with a tissue lysis buffer containing protease and phosphatase inhibitors (50 mM Tris-base $\mathrm{pH}$ 7.4, $100 \mathrm{mM}$ $\mathrm{NaCl}, 1 \%$ NP-40, $10 \mathrm{mM}$ EDTA, $20 \mathrm{mM} \mathrm{NaF}, 1 \mathrm{mM}$ PMSF, $3 \mathrm{mM} \mathrm{Na} \mathrm{VO}_{4}$, protease inhibitor mixture), the concentration of protein for each sample was determined using the Enhanced BCA Protein Assay kit (Beyotime Institute of Biotechnology, Shanghai, China). Protein samples $(20 \mu \mathrm{g})$ were separated by $10 \%$ SDS-polyacrylamide gel electrophoresis and then transferred to nitrocellulose membranes (transfer buffer: $25 \mathrm{mM}$ Tris, $190 \mathrm{mM}$ glycine, $20 \%$ methanol, $0.5 \%$ sodium dodecyl sulfate). The membranes were washed in Tris-buffered saline (TBS) (20 mM Tris-HCl, pH 7.6, $140 \mathrm{mM} \mathrm{NaCl})$ and blocked with $5 \%$ bovine serum albumin (BSA) in TBS containing $0.5 \%$ Tween-20 (TBS-T). The membranes were incubated overnight at $4^{\circ} \mathrm{C}$ with the primary antibody rabbit anti-CHIP (dilution 1:1000; Cell Signaling Technology, Inc., USA). Membranes were washed with TBS-T solution, incubated for $60 \mathrm{~min}$ with horseradish peroxidase (HRP)-conjugated mouse anti-rabbit IgG (dilution 1:3000; Upstate Biotechnology, Lake Placid, NY), washed with TBS-T, rinsed with double deionized water and immersed in enhanced chemiluminescence (ECL)detecting substrate (SuperSignalWest Pico; Pierce Chemical Co., Rockford, IL, USA). Images were captured with Micro 
Table I. Association between the mRNA expression of CHIP with histopathological features of gastric cancer patients.

\begin{tabular}{|c|c|c|c|c|c|c|}
\hline & \multirow{3}{*}{$\begin{array}{c}\text { Total }(\mathrm{n}=53) \\
\text { No. }\end{array}$} & \multicolumn{4}{|c|}{ CHIP mRNA levels } & \multirow[b]{3}{*}{ P-value } \\
\hline & & \multicolumn{2}{|c|}{ Not decreased $^{a}(n=16)$} & \multicolumn{2}{|c|}{ Decreased $^{\mathrm{a}}(\mathrm{n}=37)$} & \\
\hline & & No. & $(\%)$ & No. & $(\%)$ & \\
\hline \multicolumn{7}{|l|}{ Gender } \\
\hline Male & 32 & 8 & 25 & 24 & 75 & 0.310 \\
\hline Female & 21 & 8 & 38 & 13 & 62 & \\
\hline \multicolumn{7}{|l|}{ Age (years) } \\
\hline$\leq 55$ & 26 & 10 & 38 & 16 & 62 & 0.059 \\
\hline$>55$ & 27 & 6 & 22 & 21 & 78 & \\
\hline \multicolumn{7}{|l|}{ TNM stage } \\
\hline $\mathrm{T} 1+\mathrm{T} 2$ & 11 & 6 & 55 & 5 & 45 & 0.048 \\
\hline $\mathrm{T} 3+\mathrm{T} 4$ & 42 & 10 & 24 & 32 & 76 & \\
\hline \multicolumn{7}{|l|}{ Lymph node metastasis } \\
\hline Negative & 7 & 5 & 71 & 2 & 29 & 0.010 \\
\hline Positive & 46 & 11 & 24 & 35 & 76 & \\
\hline \multicolumn{7}{|l|}{ Differentiation } \\
\hline Poor & 45 & 12 & 27 & 33 & 73 & 0.185 \\
\hline Well and moderated & 8 & 4 & 50 & 4 & 50 & \\
\hline
\end{tabular}

${ }^{a}$ The decreased folds of $>2$ were defined as decreased and the decreased folds of $\leq 2$ were specified as not decreased.

Table II. Association between the protein levels of CHIP with clinicopathological data in gastric cancer patients.

\begin{tabular}{|c|c|c|c|c|c|c|}
\hline & \multirow{3}{*}{$\begin{array}{c}\text { Total }(\mathrm{n}=53) \\
\text { No. }\end{array}$} & \multicolumn{4}{|c|}{ CHIP expression } & \multirow[b]{3}{*}{ P-value } \\
\hline & & \multicolumn{2}{|c|}{ Not decreased $^{\mathrm{a}}(\mathrm{n}=24)$} & \multicolumn{2}{|c|}{ Decreased $^{a}(n=29)$} & \\
\hline & & No. & $(\%)$ & No. & $(\%)$ & \\
\hline \multicolumn{7}{|l|}{ Gender } \\
\hline Male & 32 & 15 & 47 & 17 & 53 & 0.774 \\
\hline Female & 21 & 9 & 43 & 12 & 57 & \\
\hline \multicolumn{7}{|l|}{ Age (years) } \\
\hline$\leq 55$ & 26 & 15 & 58 & 11 & 42 & 0.075 \\
\hline$>55$ & 27 & 9 & 33 & 18 & 67 & \\
\hline \multicolumn{7}{|l|}{ TNM stages } \\
\hline $\mathrm{T} 1+\mathrm{T} 2$ & 11 & 7 & 64 & 4 & 36 & 0.170 \\
\hline $\mathrm{T} 3+\mathrm{T} 4$ & 42 & 17 & 40 & 25 & 60 & \\
\hline \multicolumn{7}{|l|}{ Lymph node metastasis } \\
\hline Negative & 7 & 6 & 86 & 1 & 14 & 0.021 \\
\hline Positive & 46 & 18 & 39 & 28 & 61 & \\
\hline \multicolumn{7}{|l|}{ Differentiation } \\
\hline Poor & 45 & 17 & 38 & 28 & 62 & 0.009 \\
\hline Well and moderated & 8 & 7 & 87.5 & 1 & 12.5 & \\
\hline
\end{tabular}

Chemi (DNR Bio-Imaging Systems, Israel), the pictures were scanned and the optical density of the bands was determined using NIH ImageJ software (National Institutes of Health, Bethesda, MD) and was standardized to GAPDH detected using mouse anti-GAPDH monoclonal antibody (Santa Cruz Biotechnology, Inc., Santa Cruz, CA, USA). Each case of gastric cancer and the matched normal mucosa was repeated at least 3 times. 
Patient No.
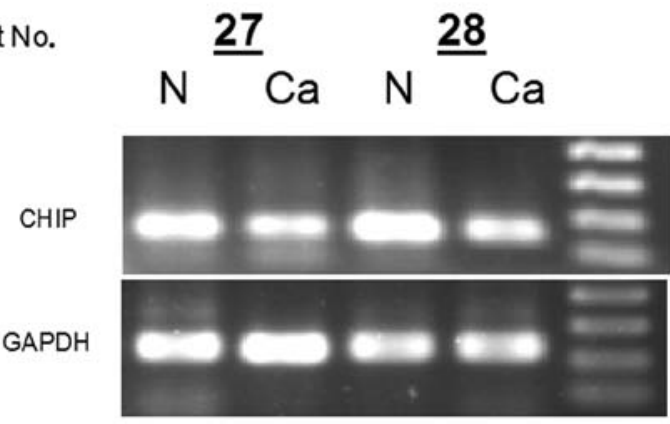

$400 \mathrm{bp}$ $300 \mathrm{bp}$ $200 \mathrm{bp}$ $100 \mathrm{bp}$ $400 \mathrm{bp}$ $300 \mathrm{bp}$ $200 \mathrm{bp}$ $100 \mathrm{bp}$
Figure 1. CHIP expression in gastric cancer samples detected by RT-PCR. The matched normal $(\mathrm{N})$ and cancerous $(\mathrm{Ca})$ samples from each gastric cancer patient were analyzed by RT-PCR using the specific primers of $C H I P$ and GAPDH $(\mathrm{n}=2)$. After the samples were normalized to GAPDH levels, the results of RT-PCR showed notably reduction in mRNA expression of $C H I P$ in cancerous tissue in contrast to normal mucosa.

Statistical analysis. The non-parametric Mann-Whitney U-test was used to analyze the mRNA expression levels of CHIP in the gastric cancerous samples and the matched normal samples of human gastric cancers. The significance of correlations between CHIP expression and clinicopathological characteristics was analyzed by Student's t-test and Pearson's $\chi^{2}$ test (Tables I and II). The continuous data were expressed as mean \pm SEM. All statistical analyses were two-sided and performed by the SPSS 13.0 software package (SPSS Inc., Chicago, IL, USA). The level of statistical significance was set at $\mathrm{P}<0.05$.

\section{Results}

Fifty-three patients suffered from gastric cancer were involved in this research. The gastric cancerous tissues and the matched normal non-cancerous tissues from each patient were detected to determine the expression of CHIP at both mRNA and protein levels. The clinicopathological characteristics including gender, age, TNM stage, lymph node metastasis and tumor differentiation of each patient were evaluated in this study.

CHIP mRNA levels were decreased in gastric cancer and the relationship with histopathologic features. The matched normal mucosa and cancerous tissue samples which were normalized to $G A P D H$ levels were detected from each GC patients $(n=2)$ by PCR (Fig. 1). The results showed mRNA levels of $C H I P$ in cancerous tissues were decreased compared with normal tissues. Furthermore, the expression of CHIP mRNA was detected in 53 gastric cancer samples and the corresponding normal samples by real-time PCR analysis. The relative mRNA expression of $C H I P$ in the gastric cancer samples was significantly lower than that in the corresponding normal samples $\left(3.44 \pm 1.33\right.$ vs. $11.40 \pm 2.87,2^{-\Delta \mathrm{Ct}}, \mathrm{P}=0.022$, paired t-test). As shown in Table I, the downregulation of CHIP expression occurred in $70 \%$ (37 of 53) of gastric cancer patients. Furthermore, the clinical significance of decreased CHIP expression correlated with the clinicopathological data was also explored. There were remarkable differences in CHIP mRNA expression in pT1/T2 stage tumors vs. pT3/ T4 stage tumors $\left(\mathrm{P}=0.048, \chi^{2}\right.$ test $)$, and lymph node non-

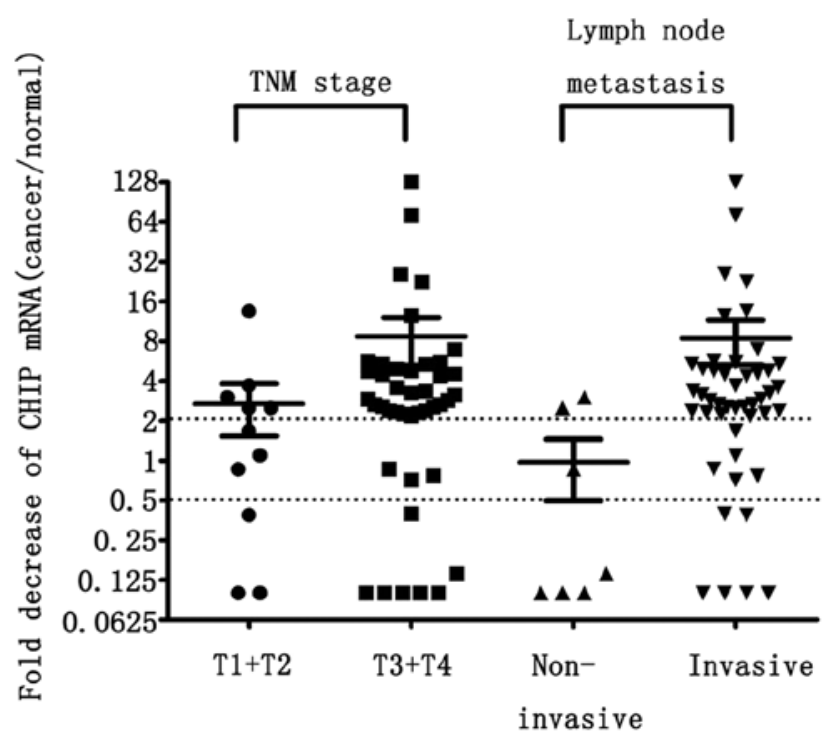

Figure 2. Expression of $C H I P$ mRNA in human gastric cancer samples compared with normal mucosa. Expression of CHIP was measured in $53 \mathrm{GC}$ patients by real-time PCR. CHIP mRNA expression was reduced in $45 \%$ (5 of 11) pT1/T2 and 76\% (32 of 42) pT3/T4, while it was decreased in 29\% (2 of 7) lymph node non-invasive tumors and 76\% (35 of 46) invasive tumors. Mean fold decreased in the tumor samples relative to normal mucosa is shown. The decreased fold of $>2$ was defined as decreased.

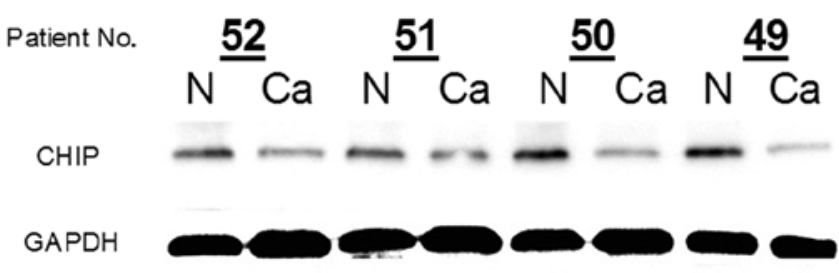

Figure 3. Western blot analysis of CHIP expression in the cancerous tissues (Ca) and adjacent normal mucosal tissues $(\mathrm{N})$ of representative primary gastric cancer patients (no. 49-52). Equal loading of protein was determined by GAPDH. Remarkable decrease of CHIP expression was observed in the cancerous tissues compared to their matched normal tissues.

invasive tumors vs. lymph node invasive tumors $(\mathrm{P}=0.01$, $\chi^{2}$ test) (Table I). CHIP mRNA was reduced 2.68 \pm 1.14 -fold in $11 \mathrm{pT} 1 / \mathrm{T} 2$ stage tumors and $8.67 \pm 3.42$-fold in $42 \mathrm{pT} 3 / \mathrm{T} 4$ stage tumors $(\mathrm{P}=0.048, \mathrm{Z}=-1.974$, Mann-Whitney U-test), respectively. In addition, CHIP mRNA was decreased $0.97 \pm 0.48$-fold in 7 lymph node non-invasive cancers and $8.41 \pm 3.13$-fold in 46 lymph node invasive cancers $(\mathrm{P}=0.008$, $\mathrm{Z}=-2.67$, Mann-Whitney U-test) (Fig. 2).

Protein expression of CHIP was downregulated in gastric cancers and the correlation with clinicopathological parameters. In this study, the protein levels of CHIP were also examined using western blot analysis. The presence of CHIP in the normal gastric mucosa was confirmed (Fig. 3). However, CHIP protein expression was notably reduced in cancerous samples compared with the matched normal mucosa in 4 cases of gastric cancer (Fig. 3). An immunohistochemical assay was used to estimate the endosomatic status of CHIP expression 

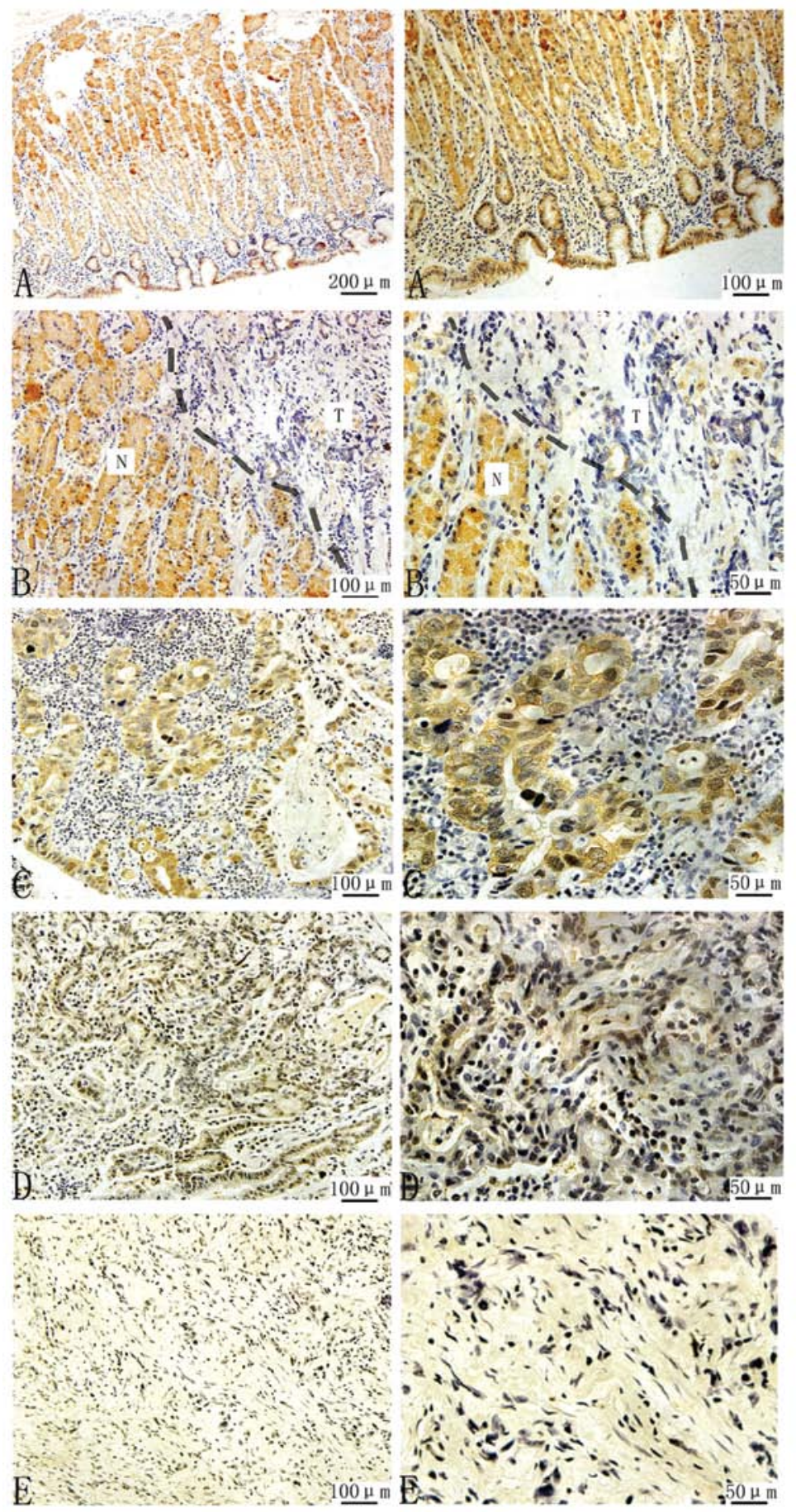

Figure 4. Representative images of immunohistochemical staining for CHIP in paraffin-embedded tissue sections. CHIP expression in (A) normal stomach; (C) well-differentiated gastric cancer; (D) moderate-differentiated gastric cancer; (E) poorly-differentiated gastric cancer. The different expression of CHIP occurred in normal $(\mathrm{N})$ or tumor $(\mathrm{T})$ tissues, which is marked with dotted lines $(\mathrm{B})$.

in normal stomach. High levels of CHIP expression occurred in non-cancerous gastric epithelial cells but not in adjacent stromal or inflammatory cells (Fig. 4A). The immunohistochemical staining was not observed in the superficial gastric foveolar cells, but was remarkable in the epithelium from the neck region to deeper glands (Fig. 4A). Therefore, CHIP was shown to align from the basal to middle portions of the gastric mucosa. CHIP staining was diffuse throughout the cytoplasm of the gastric epithelial cells (Fig. 4A). In Fig. 4B, immunohistochemical staining was remarkably decreased at the protein level of CHIP expression in cancerous tissue compared with normal tissue. However, in the cancerous sample, CHIP expression was significantly reduced in well-/ moderated-/poor-differentiated gastric cancer (Fig. 4C-E), and with the differentiation turning poor, the staining was gradually less strong. In addition, CHIP downregulation was found in 55\% (29 of 53) of gastric cancer patients (Table II). We further assessed the correlations between downregulated CHIP expression and clinicopathological features (Table II). Statistical data showed that downregulated CHIP expression 
was associated with lymph node metastasis and tumor differentiation. CHIP expression was decreased in 14\% (1 of 7) of lymph node non-invasive gastric cancer and in 61\% (28 of 46) of lymph node invasive gastric cancer $\left(\mathrm{P}=0.021, \chi^{2}\right.$ test $)$ (Table II). CHIP expression was decreased in $12.5 \%$ (1 of 8 ) of well-/moderated-differentiated gastric cancer and in $62 \%$ (28 of 45$)$ of poor-differentiated gastric cancer $\left(\mathrm{P}=0.009, \chi^{2}\right.$ test) (Table II).

\section{Discussion}

Increasing amounts of evidence strongly suggest that E3 ubiquitin ligases are involved in cancer proliferation and tumorigenesis. Furthermore, E3 ubiquitin ligases, such as murine double minute 2 (MDM2), S-phase-kinase-associated protein (Skp)-Cullin-F-Box (SCF), inhibitor of apoptosis protein have emerged as prognostic biomarkers and potential cancer drug targets (24). As a member of the E3 ubiquitin ligases, CHIP has been demonstrated to be involved in tumorigenesis, proliferation and invasion in several malignancies (21). CHIP is an E3 ubiquitin ligase that induces the ubiquitination and proteasomal degradation of its substrates. CHIP interacts with Hsp/Hsc70 and Hsp90 through its TPR domain and negatively regulates chaperone functions. The U-box domain at the carboxyl terminus of CHIP contains its E3 ubiquitin ligase activity, and was able to promote ubiquitylation and degradation of many tumor-related proteins, such as ErbB2 in breast cancer and ovarian cancer $(25,26)$. ErbB2 overexpression contributes to the evolution of a substantial group of human cancers and signifies a poor clinical prognosis (25). Previous study suggests that ErbB2 is a target of CHIP and wild-type CHIP induces ErbB2 ubiquitination and downregulation in vivo (25). CHIP overexpression results in decreased levels of endogenous ER $\alpha$ in ER $\alpha$-positive breast cancer MCF7 cells (27). In addition, CHIP interacted with Met receptor leading to proteasomal degradation of the receptor in vitro and CHIP overexpression inhibited Met-mediated lung cancer cell growth and invasion (23). Other tumor-related proteins such as p53 $(28,29)$, FOXO1 $(30,31)$ and hypoxia-inducible factor (HIF)-1- $\alpha$ (32) can also be regulated by CHIP.

Because CHIP can regulate these tumor-related proteins through ubiquitylation and degradation, it might play an important role in cancers. Kajiro et al showed that CHIP suppresses tumor progression by inhibiting oncogenic pathways in human breast cancer. Knockdown of CHIP (shCHIP) significantly enhanced the metastatic potential of the cancer cells due to increased expression of $\mathrm{Bcl} 2$, Akt1, Smad and Twist. These observations demonstrated that CHIP inhibits anchorage-independent cell growth and metastatic potential by degrading oncogenic proteins including SRC-3 (21). Interestingly, the roles of CHIP in gliomas were totally opposite to those in breast cancer. Xu et al showed that CHIP expressed stronger in high-grade gliomas than in low-grade gliomas. Glioma cells proliferation and colony formation were enhanced due to overexpression of CHIP, while knockdown of CHIP suppressed proliferation and colony formation. Notably, CHIP RNAi lentivirus significantly delayed tumor growth. In contrast, overexpression of CHIP resulted in enhanced tumor growth in a nude mouse xenograft model. This study demonstrated that CHIP contributes to oncogenesis of glioma (22).
These results indicate that CHIP might play different roles in different human cancers. However, the role of CHIP in the progression of gastric cancer has not been investigated.

In the current study, we presented some primary data that CHIP was frequently downregulated in gastric cancer using RT-PCR, real-time PCR, western blot and immunohistochemical assays. We showed CHIP was expressed in the neck and deeper glands of gastric mucosa in normal tissues. However, CHIP expression was significantly decreased in the cancerous tissues. Notably, it was almost disappeared in some highly lymph node invasive gastric cancer patients. Meanwhile, the well-differentiated and moderate-differentiated samples showed higher expression of CHIP than the poorly-differentiated gastric cancer samples. Therefore, it seems that a negative correlation exists between CHIP expression and tumor malignancy in human gastric cancer.

Invasion and metastasis of tumor cells are major causes of mortality in cancer patients. In the present study, we found that CHIP expression was almost absent in the advanced gastric cancer, such as lymph node invasive gastric cancer and poorlydifferentiated gastric cancer. Therefore, CHIP may play a significant role in the progression of gastric cancer.

Thus, further investigation on the molecular mechanism between CHIP expression and lymph node metastasis would provide some useful insight into the understanding of carcinogenesis of gastric cancer. However, our study only reported the primary data on the relationships between CHIP downregulation and clinically aggressive phenotype of gastric cancer. We showed that the decreased CHIP expression was associated with lymph node metastasis, TNM stage and tumor differentiation. Such information indicates that CHIP may be a potential diagnostic biomarker and therapeutic target for gastric cancer. However, our study only investigated the correlations between CHIP and clinicopathological characteristics of gastric cancer, and a further prospective analysis to elucidate the molecular mechanism of the downregulated CHIP in gastric cancer could be informative.

\section{Acknowledgements}

The authors express their sincere appreciation to the Department of Sugery of Tongji Hospital, Tongji Medical College, for supplying resection samples.

\section{References}

1. Parkin DM, Bray F, Ferlay J and Pisani P: Global cancer statistics, 2002. CA Cancer J Clin 55: 74-108, 2005.

2. Ferlay J, Shin HR, Bray F, Forman D, Mathers C and Parkin DM: Estimates of worldwide burden of cancer in 2008: GLOBOCAN 2008. Int J Cancer 127: 2893-2917, 2010.

3. Vogiatzi P, Vindigni C, Roviello F, Renieri A and Giordano A: Deciphering the underlying genetic and epigenetic events leading to gastric carcinogenesis. J Cell Physiol 211: 287-295, 2007.

4. Sasui W, Yokozaki H, Fujimoto J, Naka K, Kuniyasu H and Tahara E: Genetic and epigenetic alterations in multistep carcinogenesis of the stomach. J Gastroenterol 35: 111-115, 2000.

5. Lee $\mathrm{JH}, \mathrm{Han} \mathrm{SU}$, Cho H, et al: A novel germ line juxtamembrane Met mutation in human gastric cancer. Oncogene 19: 4947-4953, 2000.

6. Allgayer H, Babic R, Gruetzner KU, Tarabichi A, Schildberg FW and Heiss MM: c-erbB-2 is of independent prognostic relevance in gastric cancer and is associated with the expression of tumorassociated protease systems. J Clin Oncol 18: 2201-2209, 2000. 
7. Drebber U, Baldus SE, Nolden B, et al: The overexpression of c-met as a prognostic indicator for gastric carcinoma compared to p53 and p21 nuclear accumulation. Oncol Rep 19: 1477-1483, 2008.

8. Shiao YH, Rugge M, Correa P, Lehmann HP and Scheer WD: p53 alteration in gastric precancerous lesions. Am J Pathol 144: 511-517, 1994.

9. Ebert MP, Yu J, Hoffmann J, et al: Loss of beta-catenin expression in metastatic gastric cancer. J Clin Oncol 21: 1708-1714, 2003.

10. Wen YG, Wang Q, Zhou CZ, Qiu GQ, Peng ZH and Tang HM Mutation analysis of tumor suppressor gene PTEN in patients with gastric carcinomas and its impact on PI3K/AKT pathway. Oncol Rep 24: 89-95, 2010.

11. Sakata M, Kitamura YH, Sakuraba K, et al: Methylation of HACE1 in gastric carcinoma. Anticancer Res 29: 2231-2233, 2009.

12. Wu F, Shirahata A, Sakuraba K, et al: Down-regulation of EGFL8: a novel biomarker for advanced gastric cancer. Anticancer Res 31: 3377-3380, 2011

13. Paoletti X, Oba K, Burzykowski T, et al: Benefit of adjuvant chemotherapy for resectable gastric cancer: a meta-analysis. JAMA 303: 1729-1737, 2010.

14. Crew KD and Neugut AI: Epidemiology of gastric cancer. World J Gastroenterol 12: 354-362, 2006.

15. Anderson WF, Camargo MC, Fraumeni JF Jr, Correa P, Rosenberg PS and Rabkin CS: Age-specific trends in incidence of non-cardia gastric cancer in US adults. JAMA 303: 1723-1728, 2010.

16. Ballinger CA, Connell $\mathrm{P}, \mathrm{Wu} \mathrm{Y}, \mathrm{Hu} \mathrm{Z}$, Thompson LJ, Yin LY and Patterson C: Identification of CHIP, a novel tetratricopeptide repeat-containing protein that interacts with heat shock proteins and negatively regulates chaperone functions. Mol Cell Biol 19: 4535-4545, 1999 .

17. Lamb JR, Tugendreich S and Hieter P: Tetratricopeptide repeat interactions: to TPR or not to TPR? Trends Biochem Sci 20 257-259, 1995

18. Murata S, Minami Y, Minami M, Chiba T and Tanaka K: CHIP is a chaperone-dependent E3 ligase that ubiquitylates unfolded protein. EMBO Rep 2: 1133-1138, 2001.

19. Connell P, Ballinger CA, Jiang J, Wu Y, Thompson LJ, Hohfeld J and Patterson $\mathrm{C}$ : The co-chaperone CHIP regulates protein triage decisions mediated by heat-shock proteins. Nat Cell Biol 3: $93-96,2001$
20. Meacham GC, Patterson C, Zhang W, Younger JM and Cyr DM: The Hsc70 co-chaperone CHIP targets immature CFTR for proteasomal degradation. Nat Cell Biol 3: 100-105, 2001.

21. Kajiro M, Hirota R, Nakajima Y, et al: The ubiquitin ligase CHIP acts as an upstream regulator of oncogenic pathways. Nat Cell Biol 11: 312-319, 2009.

22. Xu T, Zhou Q, Zhou J, et al: Carboxyl terminus of Hsp70-interacting protein (CHIP) contributes to human glioma oncogenesis. Cancer Sci 102: 959-966, 2011.

23. Jang KW, Lee JE, Kim SY, et al: The C-terminus of Hsp70interacting protein promotes Met receptor degradation. J Thorac Oncol 6: 679-687, 2011.

24. Lakshmanan M, Bughani U, Duraisamy S, Diwan M, Dastidar S and Ray A: Molecular targeting of E3 ligases - a therapeutic approach for cancer. Expert Opin Ther Targets 12: 855-870, 2008.

25. Zhou P, Fernandes N, Dodge IL, et al: ErbB2 degradation mediated by the co-chaperone protein CHIP. J Biol Chem 278: 13829-13837, 2003.

26. McDonough H and Patterson C: CHIP: a link between the chaperone and proteasome systems. Cell Stress Chaperones 8: 303-308, 2003.

27. Fan M, Park A and Nephew KP: CHIP (carboxyl terminus of Hsc70-interacting protein) promotes basal and geldanamycininduced degradation of estrogen receptor- $\alpha$. Mol Endocrinol 19: 2901-2914, 2005.

28. Esser C, Scheffner M and Hohfeld J: The chaperone-associated ubiquitin ligase CHIP is able to target $\mathrm{p} 53$ for proteasomal degradation. J Biol Chem 280: 27443-27448, 2005.

29. McDonough H, Charles PC, Hilliard EG, et al: Stress-dependent Daxx-CHIP interaction suppresses the p53 apoptotic program. J Biol Chem 284: 20649-20659, 2009.

30. Huang $\mathrm{H}$ and Tindall DJ: Dynamic FoxO transcription factors. J Cell Sci 120: 2479-2487, 2007.

31. Li F, Xie P, Fan Y, et al: C terminus of Hsc70-interacting protein promotes smooth muscle cell proliferation and survival through ubiquitin-mediated degradation of FoxO1. J Biol Chem 284: 20090-20098, 2009.

32. Luo W, Zhong J, Chang R, Hu H, Pandey A and Semenza G: Hsp70 and CHIP selectively mediate ubiquitination and degradation of hypoxia-inducible factor (HIF)-1 $\alpha$ but not HIF-2 $\alpha$. J Biol Chem 285: 3651-3663, 2010. 